\author{
УДК 538.971
}

\title{
MOVEMENT OF MELT METAL LAYER AND DROPLET EROSION UNDER PLASMA FLOW ACTION TYPICAL FOR ITER TRANSIENT REGIMES
}

\author{
Yu.V. Martynenko
}

\begin{abstract}
NRC «Kurchatov Institute», National Research Nuclear University MEPhI (Moscow Engineering Physics Institute), Moscow, Russia
\end{abstract}
Models of fast melt metal layer movement and droplet erosion are presented for tokamak plasma disruption and their modeling on plasma accelerators. Plasma flow with pressure $P>1$ atm parallel to surface was shown to be reason of fast melt metal movement and droplet erosion. Pressure of plasma wind compresses the wave and steep wave moves with speed up to $v \sim 10 \mathrm{~m} / \mathrm{s}$. Capillary waves on the wave crests initiate emission of droplets with size of the order of wave length magnitude $(30-60 \mu \mathrm{m})$. On the periphery of exposed region the capillary waves result in wave crests transformation into streams which can move under its own inertia the distance $\sim 1 \mathrm{~cm}$. Besides the large scale droplets emission small droplets $\sim 1 \mu \mathrm{m}$ emission is possible due to blow away the tops of waves crest by plasma wind. Small droplets give also a contribution into material erosion. The main plasma flow above the surface is the flow of secondary shielding plasma which has high density, relatively low temperature (as compare with initial plasma flow) and high pressure. Hence even if initial plasma flow has low pressure, the secondary shielding plasma can have high pressure and result in fast melt metal movement and droplet erosion.

Key words: tokamak plasma disruption, melt layer of metal movement, droplet erosion.

\section{ДВИЖЕНИЕ РАСПЛАВЛЕННОГО СЛОЯ МЕТАЛЛА И КАПЕЛЬНАЯ ЭРОЗИЯ ПРИ ВОЗДЕЙСТВИИ ПЛАЗМЕННЫХ ПОТОКОВ, ХАРАКТЕРНЫХ ДЛЯ ПЕРЕХОДНЫХ РЕЖИМОВ ИТЭР}

\author{
Ю.В. Мартыненко
}

\section{НИЦ «Курчатовский институт», Национальный исследовательский ядерный университет «МИФИ», Москва, Россия}

Предложены модели быстрого переноса расплавленного слоя металла и капельной эрозии при срывах плазмы в токамаках и при их моделировании в плазменных ускорителях. Показано, что движение плазменного потока с давлением $P>1$ атм. над расплавленным слоем металла является причиной быстрого движения расплава и капельной эрозии. Давление плазменного ветра сжимает волну и позволяет ей двигаться со скоростью до $v \sim 10$ м/с. Капиллярные волны на валах инициируют выброс капель размером порядка длины волны 30-60 мкм. На периферии облучаемой области эта раскачка капиллярных волн приводит к разбиению валов на струи, которые по инерции могут распространяться на расстояние $\sim 1$ см. Помимо выброса крупных капель, возможен выброс мелких капель $\sim 1$ мкм, обусловленный сдуванием верхушек волн плазменным ветром. Мелкие капли дают также вклад в эрозию материала. Основной поток плазмы над расплавленным металлом - это поток вторичной экранирующей плазмы, который имеет высокую плотность, относительно низкую (по сравнению с первичной плазмой) температуру и большое давление. Поэтому даже если первичный плазменный поток имеет малое давление, вторичная экранирующая плазма может иметь большое давление и быть причиной быстрого движения расплава и капельной эрозии.

Ключевые слова: срыв плазмы в токамаке, движение расплавленного слоя металла, капельная эрозия.

\section{INTRODUCTION}

Erosion of divertor and first wall erosion is considered to be a key problem of tokamak reactor ITER. Plasma facing components are most intensively affected by plasma and heat load at transient processes such as ELM events and plasma disruption. Heat load on ITER divertor plates at ELM event is expected to be $Q=0,2-5 \mathrm{MJ} / \mathrm{m}^{2}$ for $\tau=0,1-1 \mathrm{~ms}$, and that at plasma disruption to be $Q=10-100 \mathrm{MJ} / \mathrm{m}^{2}$ for $\tau=1-10 \mathrm{~ms}[1,2]$.

Material creaking and brittle destruction studied in [3] are the most dangerous kinds of erosion. Melt metal layer transfer from one place to the other is also danger because of tinning of plasma facing material (fig. 1). This process results in most intensive tinning of lining coating, an order of magnitude higher than droplet erosion.

The same time droplet erosion at metal temperature below boiling temperature is the main process of material carry out. According to [4] fast movement

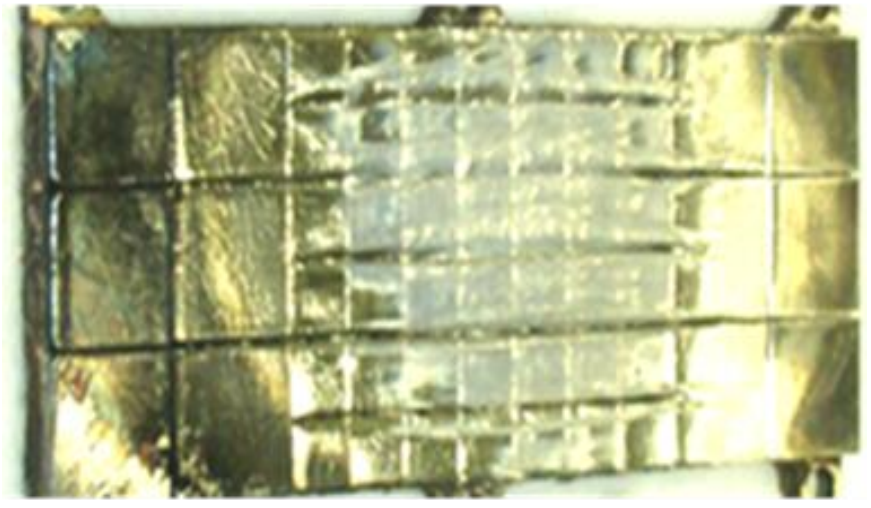

Fig. 1. Tungsten mockup after 100 QSPA plasma pulses, $Q=1,5 \mathrm{MJ} / \mathrm{m}^{2}[5]$ 
(velocity up to $\sim 10 \mathrm{~m} / \mathrm{s}$ ) of melt layer appears at metal temperature a little higher than material melting point. Therefore it is quite true [5] that hydrodynamic processes are responsible for such melt layer movement. At the same time the possible plasma pressure gradient action on melt metal is not sufficient to explain observed velocity of melt metal. Electrodynamics force considered in [6] is also too low for effect explanation.

The mentioned effects were observed on plasma accelerators in TRINITI but up to now were not found out in tokamaks [6]. Motion of melt tungsten observed in Textor [6] has much lower velocity $\mathrm{v} \approx 1 \mathrm{~cm} / \mathrm{s}$.

At the beginning we propose a model of fast displacement of melt metal from the center of plasma action region to the periphery. Then mechanisms of droplet erosion will be considered. In the last part of the paper the possibility of fast displacement of melt metal and droplet erosion in ITER will be discussed.

At melting factor $F=\mathrm{Q} \tau^{-1 / 2}$ exceeding threshold value depth of melt layer exceeds character sizes (wave length) of arising surface structure in a short time $(t<<\tau)$. Therefore we don't consider initial stage of surface melting and believe that melt layer is deep.

Tungsten is the most interesting metal for us but studied phenomena are common for the metal with boiling temperature above temperature at which fast movement of melt metal and droplet erosion begin. Therefore we will look also at experimental results obtained [4] for $\mathrm{W}, \mathrm{Nb}$ and steel.

\section{MELT METAL LAYER MOVEMENT UNDER PLASMA FLOW ACTION}

The main peculiarities of fast movement of melt metal layer are following. It was shown in Ref. [4] that initial hydrogen plasma flow strikes the target and spreads from the center to periphery of the target scraping off the part of melt layer from center to periphery (fig. 2). Material was displaced by $\sim 1 \mathrm{~cm}$ for $\sim 1 \mathrm{~ms}$. This means that movement velocity is $v \sim 10^{3} \mathrm{~cm} / \mathrm{s}$.

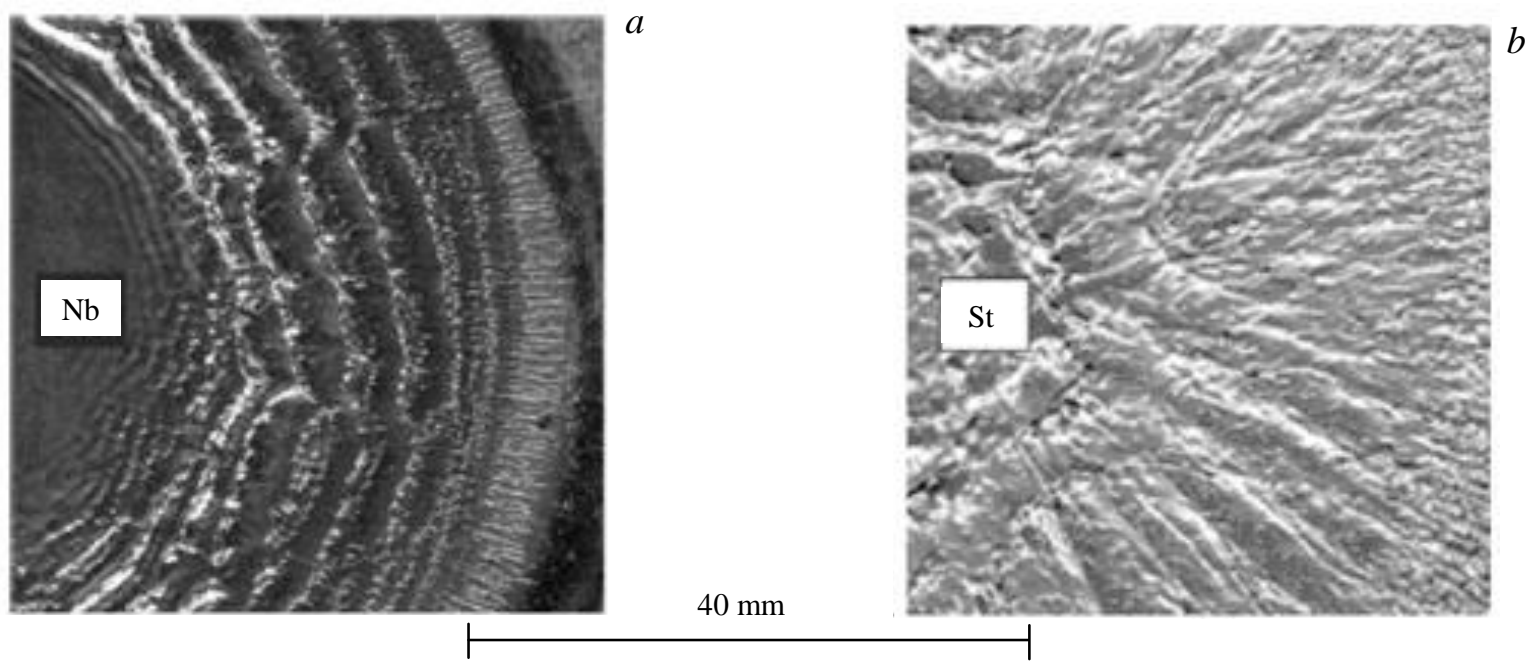

Fig. 2. Surface of $\mathrm{Nb}(a)$ and steel $(b)$ targets after 25 QSPA plasma pulses $Q=1.9 \mathrm{MJ} / \mathrm{m}^{2}$ [4]

Crater depth and radius grow with pulse heat load increase. Erosion depth in target center at $Q=2.4 \mathrm{MJ} / \mathrm{m}^{2}$ is $\sim 2 \mu \mathrm{m}$ per pulse for $\mathrm{W}$ and $\mathrm{Nb}$, whereas for steel it is $\sim 10 \mu \mathrm{m}$ per pulse. At periphery a breastwork is formed. Near periphery concentric waves are seen. In some cases waves transform into radial directed streams.

Waves appearance suggests that waves arise due to Kelvin-Helmholtz instability at plasma flow directed radial from center to periphery over melt metal. This suggestion was made already in the first work [7] where waves created by plasma flow over melt metal were observed.

In this case wave length, frequency and increment are following

$$
\begin{gathered}
\lambda=3 \pi \alpha / \rho^{\prime} U^{2} ; \\
\omega=(2 \pi U / \lambda)\left(\rho^{\prime} /\left(\rho+\rho^{\prime}\right)\right) ; \\
\gamma=\left\{2 \rho^{\prime} U^{3} / 3 \alpha\right\}\left(\rho^{\prime} / 3 \rho\right)^{1 / 2},
\end{gathered}
$$

where $\alpha$ is the surface tension, $\rho^{\prime}$ and $U$ are density and velocity of plasma flow, $\rho$ is the metal density, $P=\rho^{\prime} U^{2} / 2$ is the pressure of plasma flow. It is noticeable that $\omega<<\gamma$ by $(3 \rho / \rho)^{1 / 2} \approx 10^{3}$ times. Noticeable that as 
it was observer in [7] wave length decrease and $\omega$ and $\gamma$ increase with increase of plasma flow pressure. At typical parameters of plasma flow $Q=1.4 \mathrm{MJ} / \mathrm{m}^{2}, P=2 \mathrm{~atm}, \tau=1 \mathrm{~ms}$ (these values will be used for estimations) for melt tungsten $\lambda \approx 50 \mu \mathrm{m}, \omega \approx 10^{3} \mathrm{~s}^{-1}, \gamma \approx 10^{6} \mathrm{~s}^{-1}$. Thus at pulse duration $\tau=1 \mathrm{~ms}$ there is not wave motion, instability expresses as exponential growth of wave structure. One should note that plasma flow over the metal surface is not only plasma of initial flow but also plasma of evaporated metal. This will be discussed in details in the last section.

However wave crests growth can be considered in linear approximation only up to height

$$
H_{0}=(\chi / \gamma)^{1 / 2} \sim 3 \cdot 10^{-4} \mathrm{~cm},
$$

( $\chi$ is the kinematic viscosity), when one can neglect the viscosity. At $H>H_{0}$ wave height growth should be described using Navier-Stokes equations for liquid flow to wave crest. The driving force is Bernoulli pressure gradient between crest and valley of wave [8]. In this case growth of wave height $\mathrm{H}$ is described by equation [8]

$$
d H / d t=\left(\rho^{\prime} / \rho\right) U^{2} h^{3} /\left(\lambda^{2} \chi\right)=A H^{3}, \quad A=\left(\frac{\rho^{\prime} U^{2}}{\rho \lambda^{2} \chi}\right) .
$$

However plasma wind pressure deforms wave profile. Wind pressure $P$ is balanced by surface tension pressure at lee side (fig. 3)

$$
P=\alpha / r .
$$

We emphasize that $P=\rho^{\prime} U^{2} / 2$ is the pressure of plasma flow moving parallel to surface. Radius of curvature on wave lee side is $r \approx\left(d^{2} y / d x^{2}\right)^{-1} \approx S^{2} / H$.

As a result sole length of wave is

$$
S=(\alpha H / P)^{1 / 2} .
$$

Volume of the wave is constant because development of Kelvin-Helmholtz instability and wave height growth decease at balance of plasma wind pressure and surface tension pressure. With some uncertainty we believe

$$
\lambda H_{0}=S H .
$$

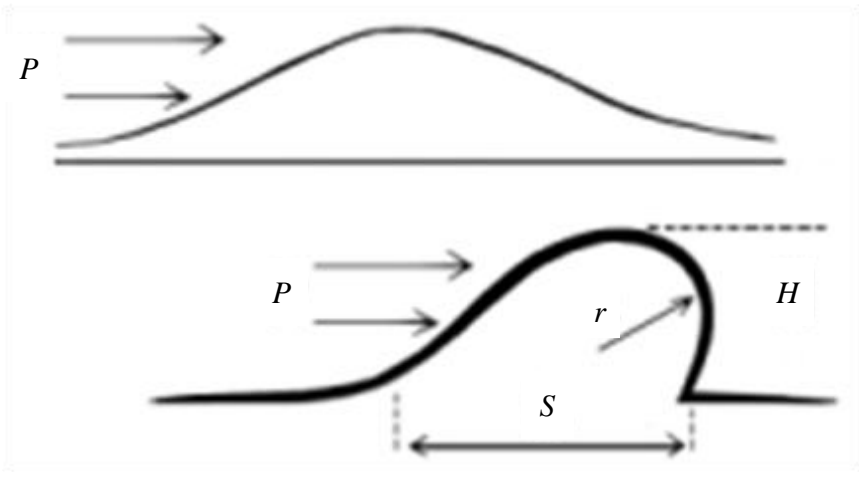

Then from (1), (4), (7) and (8) we receive

$$
\begin{gathered}
H=B(P)^{-1 / 2}(U)^{-1 / 2} ; B=(3)^{7 / 4}(2)^{-2 / 3}(\pi)^{3 / 2}(\alpha)^{1 / 2}(\chi)^{1 / 2}\left(\rho / \rho^{\prime}\right)^{1 / 4} ; \\
B \approx 24(\alpha)^{1 / 2}(\chi)^{1 / 2}\left(\rho / \rho^{\prime}\right)^{1 / 4} ; \\
S=B^{1 / 3} \alpha(P)^{-5 / 6}(U)^{-1 / 6} .
\end{gathered}
$$

For example plasma flow $\left(Q=1.4 \mathrm{MJ} / \mathrm{m}^{2}, P=2\right.$ atm, $\left.\tau=1 \mathrm{~ms}\right)$ on tungsten $S\langle\lambda$, and $H\rangle H_{0}$. It means that area $H$ on which plasma wind action increases after deformation and area $S$ of wave contact with substrate decreases (here and below areas are related per a unit of wave crest length). The crest glides on the surface with velocity higher than initial velocity of wave. Velocity of wave crest can be determined from equality of plasma pressure force and friction force

$$
F=\rho \chi v S / H \text {. }
$$

Hence velocity of the crest is

$$
v=G P^{5 / 6} ; G=(2 / \rho \alpha \chi)(B / U)^{5 / 3} .
$$

For example plasma flow ( $Q=1.4 \mathrm{MJ} / \mathrm{m}^{2}, P=2 \mathrm{~atm}, \tau=1 \mathrm{~ms}$ ) velocity of tungsten wave crest is $v \sim 10 \mathrm{~m} / \mathrm{s}$. Wave crests on more light metals move with higher velocity $(v \sim 1 / \rho)$.

Wave crest velocity is maximal at places where tangential plasma flow pressure is maximal.

On target center plasma pressure acts mainly normal to surface, maximal tangential pressure was observed at radius $\sim 30 \mathrm{~mm}$. At this radius crater depth is maximal. If melt material shift would be determined by pressure gradient maximal crater depth will be in center. 


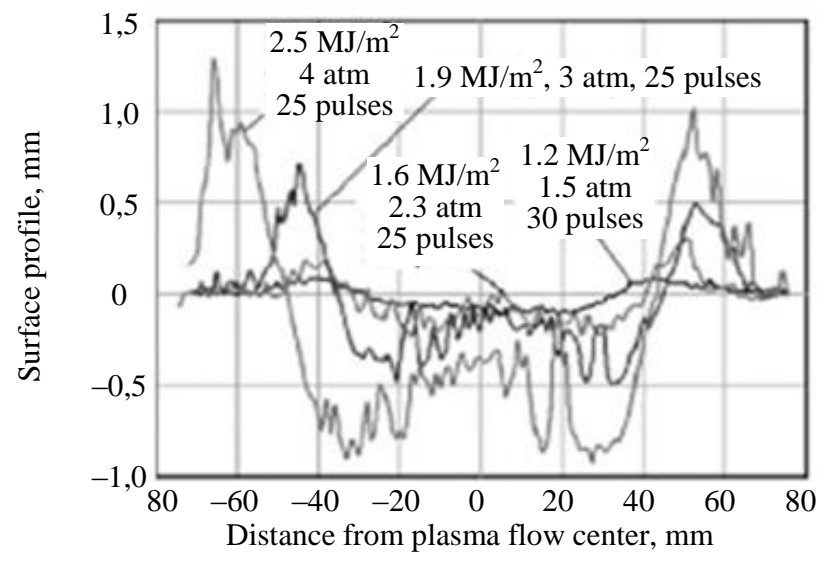

Fig. 4. Profile of steel target for different plasma loads [4]

At plasma flow pressure decrease, for example at wave exit to periphery, wave crest broadens. This means that sole $\mathrm{S}$ increases and wave height $\mathrm{H}$ decreases. Hence velocity decreases as $v \sim P^{4}$. However wave crest has inertia. Really for friction force (10) wave velocity decreases after plasma wind decease as

$$
d v / d t=v d v / d x=-F / \rho S H ; v=v_{0}(1-x / L) ; \mathrm{L}=v_{0} H^{2} / \chi .
$$

For example plasma flow $\left(Q=1.4 \mathrm{MJ} / \mathrm{m}^{2}\right.$, $P=2 \mathrm{~atm}, \tau=1 \mathrm{~ms}) L \approx(1-3) \cdot 10^{-2} \mathrm{~m}$. Wave crests inertia explains increase of crater radius with plasma flow pressure increase, crater radius being larger than initial plasma flow radius (fig. 4 [4]).

\section{DEPTH OF EROSION CAUSED BY SHIFT OF MELT LAYER FROM CENTER TO PERIPHERY OF CRATER}

Maximal depth of crater $\mathrm{d}$ created for a pulse can be estimated knowing crest volume $S H$, distance between waves crests $\lambda$ and the number of waves leaving the crater $n$ during the pulse $\tau$. We believe that $n=v \tau / R$, where $R$ is the crater radius. Than the crater depth is

$$
d=n S H / \lambda \text {. }
$$

For tungsten at example plasma flow $\left(Q=1.4 \mathrm{MJ} / \mathrm{m}^{2}, P=2 \mathrm{~atm}, \tau=1 \mathrm{~ms}\right) d \sim 20 \mu \mathrm{m}$. For the majority of light metals $d$ is higher. This estimate agrees with results [4] shown in the fig. 4 for steel.

Maximal depth is situated not at crater center.

\section{SURFACE RELIEF AFTER SOLIDIFICATION}

Note that after plasma load cessation surface relief is smoothing due to surface tension action. Taking into account that surface tension pressure approximately equals to plasma flow pressure and believe the smoothing means wave broadening on distance $\sim S$ for time cooling to solidification $t_{\mathrm{c}}$, we obtain condition of wave solidification

$$
P>0.08 U^{2 / 5} \alpha^{4 / 5} \chi^{1 / 5} \rho^{1 / 5} \rho^{2 / 5} t_{c}^{3 / 5} .
$$

This condition means that at high pressure, at center plasma flow, waves have time to smooth but at periphery large waves are seen after solidification.

\section{WAVE TRANSFORMATION INTO STREAMS}

Concentric waves taking away melt material from crater were observed [4] to transform into streams at crater periphery. This transformation can be described by following scenario.

Capillary waves arise on wave crest moving along the crest with dispersion law (approximate equation means neglect specific crest shape which determines a numerical factor)

$$
\omega_{1}^{2} \approx(\alpha / \rho) k^{3}, k=2 \pi / \ell,
$$

$\ell$ is the capillary wave length. Crest motion increases vibrations if their frequency coincides with crest velocity divided by capillary wave length $\omega_{1}=v / \ell$. At inertial motion crest vibration transforms into streams with width $\ell$ :

$$
\ell \approx(2 \pi)^{3} \alpha / \rho v^{2}=(2 \pi)^{3} \alpha /\left(\rho G^{2} P^{5 / 3}\right) .
$$

On crater periphery crest vibrations result in crest bending (see fig. $2 a$ ) and then into streams transformation (see fig. $2 b$ ). At central region vibrations are reason of droplet emission. 


\section{DROPLET EROSION}

Work [9] shows that droplet emission from melt tungsten begins at temperature a little higher then melting point $\left(Q=1 \mathrm{MJ} / \mathrm{m}^{2}\right)$. At $Q=1-1.2 \mathrm{MJ} / \mathrm{m}^{2}$ droplet emission is not regular, droplets number per pulse is from 0 to 50 . At $Q>1.2 \mathrm{MJ} / \mathrm{m}^{2}$ droplet emission is regular and symmetric as respect to initial plasma flow axis. Droplets escape at angle $<45^{\circ}$ to surface. Droplet sizes are several tens of $\mu \mathrm{m}$, it is the same order of magnitude as wave length. Droplet size was observed (fig. 6 [10]) to increase with $Q$ growth (fig. 5).

However in earlier works (fig. 6, [10]) performed also in TRINITI but on plasma accelerator MKT $\left(Q=0.3 \mathrm{MJ} / \mathrm{m}^{2}, \tau=60 \mu \mathrm{s}, W=5 \mathrm{GW} / \mathrm{mm}\right.$, deuterium ion energy $\left.1-2 \mathrm{keV}, P=10^{-2} \mathrm{~atm}\right)$ droplet emission was also observed. But droplet size $d \approx 1 \mu \mathrm{m}$ was 1.5 orders of magnitude lower than wave length $\sim 30 \mu \mathrm{m}$, of visible surface structure. The same time model [11] was proposed which explain small droplet emission as blow away tops of wave crest by plasma wind. Note that plasma flow pressure in MKT accelerator was lower than required for wave structure development and droplet erosion. According to (1) at pressure of MKT plasma flow wave length of Kelvin-Helmholtz instability is $\sim 1 \mathrm{~cm}$ and increment $\gamma \ll \tau^{-1}$. Wave structure development is understandable if we take into account that initial plasma flow evaporates tungsten and vapor plasma has high density, low temperature and high pressure. Flow of secondary plasma is reason of wave structure formation and droplet erosion.

Droplet emission observed in [9] was explained [12] on base exponential wave growth due to KelvinHelmholtz instability.

Going from model of wave crest movement we

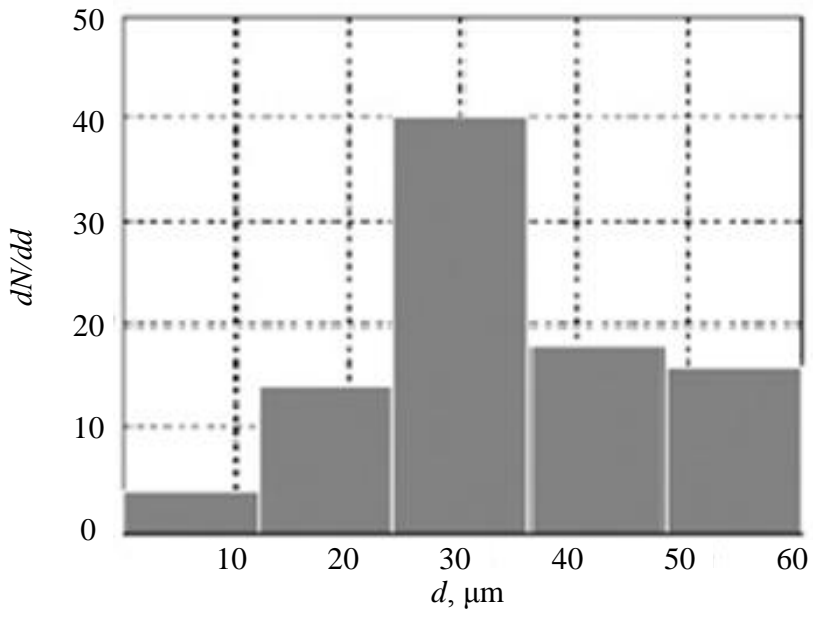

Fig. 5. Size distribution of tungsten droplets for normal directed plasma flow at $Q=1.6 \mathrm{MJ} / \mathrm{m}^{2}[9]$

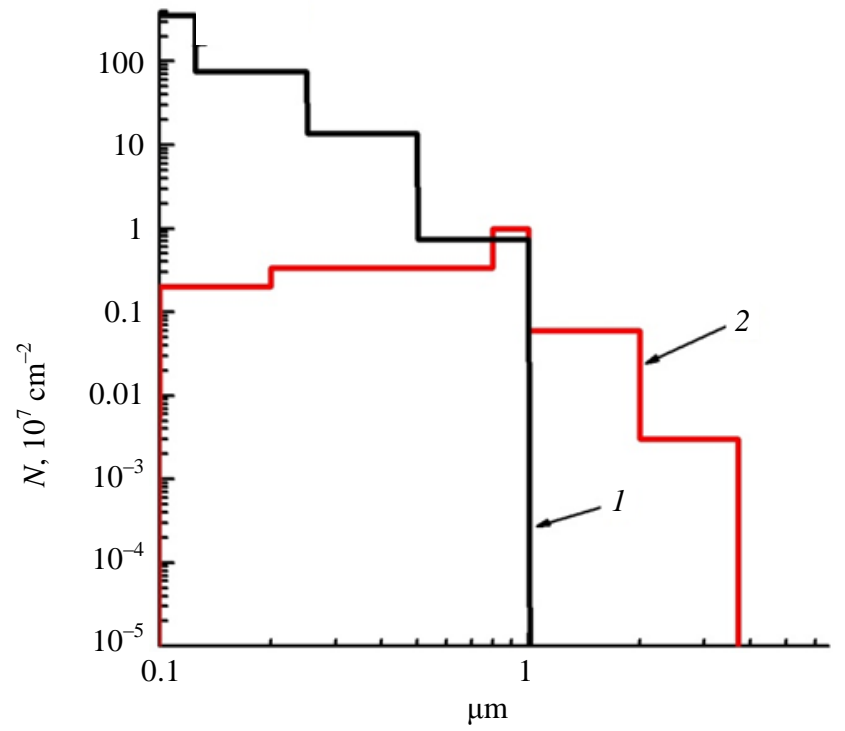

Fig. 6. Size distribution of tungsten droplets on Si collector, collecting droplets escaping near (parallel) to target surface (1) and droplets returned to target (2) [10] propose the following model of droplet emission which explains droplet size and droplet escape angle distribution.

Kinetic energy of sliding crest $H S \rho v^{2} / 2$ exceeds adhesion energy of crest with substrate $\alpha S$. But the crest can't be departed from substrate until receive normal velocity component. It occurs when one wave catch up foregoing wave. The most probable that part of wave crest with length $\ell$ accelerates due to vibration, catch up foregoing wave crest crawls on it and departures at the angle $\phi\left(\sin \phi \approx H / S \approx 45^{\circ}\right)$. This explains angle distribution of escaping droplets. Velocity of crest catching up as respect to foregoing wave is $v_{1}=\ell \omega_{1}$. Kinetic energy $E_{k}=\ell H S \rho v_{1}^{2} / 2$ is spent to droplet formation. We propose that droplet at departure moment is a tongue with width $\ell$ and length $L$. From equation $E_{k}=\alpha \ell L$ we obtain tongue length

$$
\begin{gathered}
L=\ell H S \rho\left(v_{1}\right)^{2} /(2 \alpha \ell) \sim P^{1 / 3} ; \\
d=\{\ell H L\}^{1 / 3} \sim P^{-1 / 3},
\end{gathered}
$$

Droplet size (17) slowly decreases with pressure increase in contrast to result of [9]. However droplet size in [9] was determined by rate of droplet temperature decrease. Work [9] shows that droplet size increases with increase of initial plasma flow pressure. Effect of droplet heating as a result of Richardson effect [13] was not taken into account. At thermal electron emission every emitting electron takes away energy equal thermal ener- 
gy of electron in droplet 3T/2 (+ work function). But for charge balance an electron from plasma comes to droplet and brings energy equal thermal energy of plasma electron $3 T_{e} / 2$ (+ work function). At $T_{e}>T$ droplet heating occurs being higher at higher $T_{e}$. Increase of power density of initial plasma flow results in increase of droplet temperature it luminosity and visibility of droplet size.

More enhanced target mass loss at power density increase as compare with emitting droplets number increase can be explained by small size droplets $(\sim 1 \mu \mathrm{m})$ emission which was observed in work [10] and occurs due to blowing away tops of wave crest by plasma wind. We believe that the both mechanisms droplets emission (small and large) work simultaneously independent. In work [9] droplets with size $<5 \mu \mathrm{m}$ can't be detected. Besides small droplets can be evaporated before registration [11]. Small droplets also give an input to erosion. The same time small droplets disturb plasma not too mach due to low length to evaporation.

Lower velocity of escaping droplets at high power density of initial plasma flow can be explained by increase of shielding plasma viscosity at enhanced heating by initial plasma flow.

\section{FAST MOVEMENT OF MELT LAYER AND DROPLET EROSION IN ITER}

Parameters comparison of plasma accelerator QSPA and parameters of expected plasma flow at disruption in ITER was made in work [12]. On the base of this comparison conclusion was made that droplet erosion observed on QSPA will not take place in ITER because of low plasma pressure in ITER: $P=1-10$ atm in QSPA and $P<0.2 \mathrm{~atm}$ in ITER. With approximately equal power densities in QSPA and ITER particles energies in plasma flows of QSPA and ITER differ an order of magnitude: $300 \mathrm{eV}$ in QSPA and $3 \mathrm{keV}$ in ITER.

However work [10] had shown that at high enough power density of plasma flow even at low flow pressure $P=10^{-2}$ atm dense shielding plasma is formed with relatively low temperature $(T<100 \mathrm{eV})$ and high flow pressure. Shielding plasma flow along the surface causes fast movement of melt metal and intensive droplet erosion.

The main factor determined shielding plasma formation is power density. But it should be noted that droplets evaporation gives input in shielding plasma formation. Shielding plasma creation can begin with evaporation of surface contamination, mobilized dust particles and so on. After start of droplet emission shielding plasma existence will be supported by droplets evaporation.

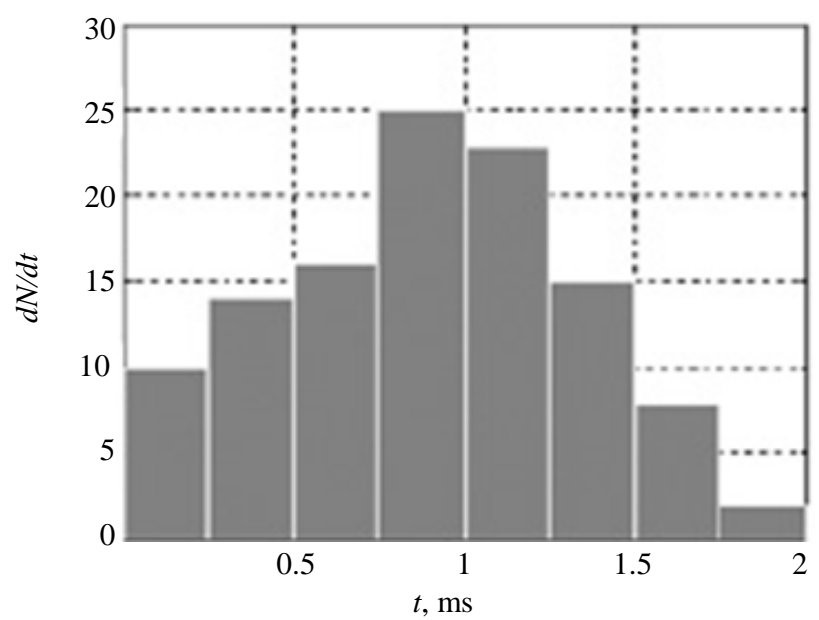

Fig. 7. Tungsten droplets distribution on time of escape. Normal incidence of plasma flow, $Q=1.6 \mathrm{MJ} / \mathrm{m}^{2}, \tau=0.5 \mathrm{~ms}$ [9]

Other evidence of shielding plasma influence on droplet emission is time dependence of droplets ejection received in [9] (fig. 7). Main droplets escape occurs after QSPA pulse completion. Pulse duration is $0.5 \mathrm{~ms}$ whereas maximal droplet emission was observed at $1 \mathrm{~ms}$ and droplet emission lasted up to $2 \mathrm{~ms}$. This means that droplet emission was initiated by shielding plasma which flows away slowly and regenerates by target evaporation caused by shielding plasma action.

In the nineties a number of works $[14,15]$ were performed on shielding plasma investigation. These works show that density of shielding plasma can reach $10^{23} \mathrm{~m}^{-3}$ and temperature is some tens $\mathrm{eV}$. Processes in plasma of metal vapor are complicated and require consideration not only plasma dynamic but also investigation of atomic levels population and radiation transport.

Analysis of works $[9,11]$ shows that use of parameter of initial plasma flow for estimation of melt metal layer motion and droplet erosion is not correct. For quantity calculations of melt layer movement and droplet erosion investigations of shielding plasma characteristic in dependence of initial plasma flow are required.

\section{CONCLUSION}

Analysis of experimental data and models gives scenarios of fast movement of melt metal layer and droplet erosion caused by plasma disruption in tokamaks and on plasma accelerators simulating plasma disruption. The following conclusions are made. 
1. Plasma flow with pressure $P>1$ atm over melt metal results in wave formation caused by KelvinHelmholtz instability. Waves move under plasma wind. Plasma wind pressure compresses wave decreasing contact area of the wave and substrate and increasing wave height. Such steep wave slides on surface with velocity up to $v \sim 10 \mathrm{~m} / \mathrm{s}$. This is reason of deep crater formation in center of plasma flow.

2. Instability of moving wave crest results in capillary waves appearance on wave crests. In center of irradiated region one wave due to capillary waves catches on other and initiates emission of droplets with size $30-60 \mu \mathrm{m}$. On periphery of irradiated region capillary waves transform concentric waves into separated streams. The streams can spread on distance $1 \mathrm{~cm}$ by inertia.

3. Besides large-scale droplets emission small size $(\sim 1 \mu \mathrm{m})$ droplet emission is possible. Small droplet emission is caused by plasma wind blow away tops of wave crest. Small droplets give input in target mass loss.

4. Main plasma stream over melt metal is flow of secondary shielding plasma which has high density relatively low (as compare initial plasma flow) temperature and high pressure. For quantity calculations of melt layer movement and droplet erosion investigations of shielding plasma characteristic in dependence of initial plasma flow are required.

\section{REFERENCES}

1. ITER Physics Basis. - Nucler Fusion, 1999, vol. 39, p. 2137.

2. Federici G., Scinner C.H., Brooks J.N. et al. - Nuclear Fusion, 2001, vol. 41, p. 1967.

3. Budaev V.P., Martynenko Yu.V., Khimchenko L.N., Zhitlukhin A.M., Klimov N.S., Pitts R.A., Linke J., Bazylev B., Belova N.E., Karpov A.V., Kovalenko D.V., Podkovyrov V.L., Yaroshevskaya A.D. Recrystallization and modification of the stainless-steel surface relief under photonic heat load in powerful plasma discharges. - Plasma Physics Reports, 2013, vol. 39, № 11, pp. 910924.

4. Poznyak I.M., Klimov N.S., Podkovyrov V.L., Safronov V.M., Zhytlukhin A.M., Kovalenko D.V. Erision of metals udar the action of intense plasma stream. - Problems of Atomic Science and Technology. Ser. Thermonuclear Fusion, 2012, № 4, p. 23.

5. Zhytlukhin A.M. - In: Workshop on ITER first wall and diverter. Zvenigorod. 14 February, 2012.

6. Bazylev B. Modeling of W melting experiments and extrapolation for ITER. — In: 17th ITPA Meeting on Divertor-SOL Physics. 15-17 October 2012.

7. Bakhtin V.P., Vasiliev V.I., Grebenstchikov Yu.B., Konkashbaev I.K., Kucheryavyi Yu.V., Myanko V.I., Strunnikov V.M. Wave generation on melt metal surface by plasma flow. — In: 1st All Union Conf. «Constructive Materials Properties Modification by Beams of Charged Particles». Part I, 1988, pp. 108-110.

8. Martynenko Yu.V. Metal surface erosion as result of wave relief formation under intensive plasma flow. — Problems of Atomic Science and Technology. Ser. Thermonuclear Fusion. 2012, № 3, pp. 41-43.

9. Klimov N.S., Podkovyrov V.L., Zhytlukhin A.M., Safronov V.M., Kovalenko D.V., Moskacheva A.A., Poznyak I.M. Tungsten splashing ubder intensive plasma flow. - Problems of Atomic Science and Technology. Ser. Thermonuclear Fusion, 2009 , № 2, p. 52.

10. Guseva M.I., Gureev V.M., Domantovskii A.G., Martynenko Yu.V., Moskovkin P.G., Stolyarova V.G., Strunnikov V.M., Plyashkevich L.N., Vasiliev V.I. Tungsten surface erosion and erosion product morphology in experiments simulating plasma disruption. - J. Techn. Phys., 2002, vol. 72, № 7, pp. 40-51.

11. Martynenko Yu.V., Moskovkin P.G. About droplet erosion at plasma disruption in tokamaks. — Problems of Atomic Science and Technology. Ser. Thermonuclear Fusion, 2000, № 1, pp. 65-69.

12. Bazylev B., Janeschitz G., Landman I., Laorte F., Klimov N.S., Podkovyrov V.L., Safronov V.M. Experimental and theoretical investigation of droplet emission from tungsten melt layer. - Fusion Engineering and Design, 2009, vol. 84, pp. 441—445.

13. Martynenko Yu.V., Nagel’ M.Yu., Orlov M.A. A nanoparticle in plasma. — Plasma Physics Reports, 2009, vol. 35, № 6, pp. 494498.

14. Hassanein A., Konkashbaev I. Comprehensive model for disruption erosion in a reactor environment. — J. Nucl. Mat., 1995, April, vol. $220-222$, pp. $244-248$.

15. Karlykhanov N.G., Martynenko Yu.V., Matveeko Yu.I., Moskovkin P.G., Plitov V.Yu. Interaction of a plasma flow with a solid target. — Plasma Physics Reports, 1996, vol. 22, № 11, p. 903.

\section{AUTHORS}

Martynenko Yu.V. NRC “Kurchatov Institute”, pl. Kurchatova 1, 123182 Moscow, Rusia; martyn@nfi.kiae.ru 